\title{
OPTIMATION OF ETHANOL EXTRACT OF CENTELLA ASIATICA AND CRESINTIA CUJETE COMPOSITION AS NATURAL ANTIOXIDANT SOURCE
}

\author{
${ }^{1}$ Mustofa Ahda, ${ }^{1}$ Fiqrirozi, ${ }^{1}$ Gina Noor Habibah, ${ }^{1}$ Mas Ulfah Lestari, ${ }^{1}$ Tomy \\ Hardianto, ${ }^{1}$ Yuni Andriani \\ ${ }^{1}$ Fakultas Farmasi Universitas Ahmad Dahlan \\ Jln. Prof. Dr. Supomo Yogyakarta, Telp. (0274) 379418 \\ Email: mustofa_ahda@yahoo.com
}

\begin{abstract}
ABSTRAK
Pengembangan antioksidan alami dalam pemanfaatan pegagan (Centella asiatica) dan majapahit (Cresintia cujete) merupakan potensi yang besar. Penelitian ini telah melakukan optimasi komposisi ekstrak etanol pegagan (Centella asiatica) dan majapahit (Cresintia cujete) sebagai sumber antioksidan dengan dilakukan uji aktifitas penangkapan radikal bebas terhadap DPPH. Hasil penelitian menunjukkan bahwa baik ekstrak etanol pegagan (Centella asiatica) dan majapahit (Cresintia cujete) memiliki kandungan total fenol yang ditunjukkan dengan adanya kemampuan mereduksi reagen Folin Ciocalteu menjadi berwarna biru. Hasil optimasi komposisi ekstrak pegagan (Centella asiatica): majapahit (Cresintia cujete) $=30: 70$ memiliki aktifitas penangkapan radikal bebas terhadap DPPH yang paling baik dibandingkan ekstraks etanol pegagan (Centella asiatica) dan majapahit (Cresintia cujete). Nilai $\mathrm{IC}_{50}$ untuk komposisi ekstrak etanol pegagan (Centella asiatica): majapahit $($ Cresintia cujete $)=30: 70$ sebesar $0,103 \mathrm{mg} / \mathrm{mL}$.
\end{abstract}

Kata Kunci: Aktifitas Antioksidan, pegagan (Centella asiatica), majapahit (Cresintia cujete), Komposisi Ekstrak

\begin{abstract}
The development of natural antioxidants in the Pegagan (Centella asiatica) and Majapahit (Cresintia cujete) is a great potential. This research has been optimizing the composition of ethanol extract of Centella asiatica and Cresintia cujete as an antioxidants source using measure the free radicals scavenging activity of DPPH. The results of research showed that both the ethanol extract of Centella asiatica and Cresintia cujete has a total phenol content. its shown with the ability to reduce reagent Folin Ciocalteu become blue colour. The composition optimazion of extract Centella asiatica:Cresintia cujete $=30: 70$ has free radical scavenging activity of DPPH most well compared ethanol extract of Centella asiatica and Cresintia cujete. $\mathrm{IC}_{50}$ values for the composition of ethanol extract of Centella asiatica:Cresintia cujete $=30: 70$ is $0,103 \mathrm{mg} / \mathrm{mL}$.
\end{abstract}

Keywords: Antioxidant activity, Centella asiatica, Cresintia cujete, Composition Extract

\section{Pendahuluan}

Di Indonesia, radikal bebas hasil polusi sangat meningkat tiap tahunnya.
Asap rokok, makanan yang digoreng, dibakar, paparan sinar matahari berlebih, asap kendaraan bermotor, obat-obat 
tertentu, racun dan polusi udara merupakan beberapa sumber pembentuk senyawa radikal bebas. Senyawa radikal bebas yang berlebihan dapat memberikan dampak yang merugikan bagi kesehatan, seperti jantung koroner, katarak, gangguan kognisi dan kanker. Manusia telah memiliki sistem pertahanan terhadap oksidan yang berasal dari dalam tubuh ataupun dari luar berupa diet. Pertahanan dari dalam tubuh seperti enzim-enzim peroksidase, katalase, glutation, histidin-peptidin seringkali masih kurang akibat pengaruh lingkungan dan diet yang buruk (Pietta,1999).

Hal ini perlu menjadi perhatian dalam menemukan tanaman sebagai sumber baru untuk antioksidan, terutama yang aman, murah dan mudah untuk diperoleh masyarakat. Beberapa sumber antioksidan yang mudah diperoleh seperti pegagan (Centella asiatica) dan majapahit (Cresintia cujete). Senyawa aktif yang terdapat dalam pegagan (Centella asiatica) seperti triterpen (Herlina, 2010), asam asiatik dan asitikosid (Kim dkk., 2009), flavonoid, tanin, saponin (Sutrisno dkk., 2014). Sedangkan dalam majapahit (Cresintia cujete) memiliki kandungan senyawa aktif yaitu saponins, flavonoid, cardenolides, tannins and phenol (Ejelonu dkk., 2011).
Banyak penelitian yang telah melaporkan tentang manfaat pegagan (Centella asiatica). Ekstraks pegagan (Centella asiatica) dengan senyawa aktif triterpen dapat meningkatkan fungsi kognitif belajar dan mengingat pada mencit jantan albino (Herlina, 2010). Selain itu, Sutrisno dkk., (2014) juga melaporkan manfaat ekstrak etanol pegagan (Centella asiatica) memiliki kemampuan daya hambat terhadap Pseudomonas aeruginosa dan Staphylococcus aureus.

Sedangkan majapahit (Cresintia cujete) menurut Mahbub dkk, (2011) melaporkan bahwa majapahit (Cresintia cujete) ini memiliki kemampuan penghambatan zona pada aktivitas antibakteri dari ekstraks etanol majapahit (Cresintia cujete) dengan konsentrasi sebesar 8 mg/lubang dan Minimum Inhibitory Concentration (MIC) sebesar $2500 \mathrm{ug} / \mathrm{mL}$. Kemampuan antibakteri hasil ektraks alkohol majapahit (Cresintia cujete) mampu menghambat Mycobacterium tuberculosis (Agarwal dan Chauhan, 2015). Menurut Das dkk., (2014), menyatakan bahwa majapahit (Cresintia cujete) ini memiliki aktivitas penangkapan radikal bebas DPPH yang sangat baik dengan nilai $\mathrm{IC}_{50}$ sebesar $8,78 \mathrm{ug} / \mathrm{mL}$. 
Oleh karena itu, Manfaat pegagan (Centella asiatica):majapahit (Cresintia cujete) yang besar dan dapat digunakan sebagai antioksidan dan antibakteri. Hal ini mendorong penelitian kali ini membahas tentang komposisi antara ekstraks etanol pegagan (Centella asiatica):majapahit (Cresintia cujete) yang paling optimum dalam melakukan penghambatan radikal bebas DPPH. Optimasi komposisi ekstraks etanol pegagan (Centella asiatica): majapahit (Cresintia cujete) ini diharapkan mampu menemukan efek sinergis senyawa aktif yang ada pada pegagan (Centella asiatica) dan majapahit (Cresintia cujete).

\section{Tujuan Penelitian}

Penelitian ini bertujuan melakukan optimasi kombinasi ekstraks etanol pegagan (Centella asiatica):majapahit (Cresintia cujete) sebagai kandidat obat herbal.

\section{Metode Penelitian}

\section{Bahan}

Bahan baku yang digunakan adalah pegagan (Centella asiatica) dan majapahit (Cresintia cujete) (tanaman berasal dari merapi farma), Etanol sebagai pengekstrak. Bahan kimia lainnya adalah metanol, aquadest, Pereaksi Folin Ciocalteu dan Larutan DPPH 0,05 mM.

Alat
Alat-alat yang digunakan dalam penelitian ini adalah beaker glass, labu takar, erlenmeyer, corong, kertas saring, timbangan analitik, rotary evaporator vakum, Spektrometer Uv-vis Shimadzu 1700 dan Spektrometer FTIR Shimadzu FTIR 8201 Prestige 21.

\section{Prosedur Penelitian}

\section{Proses Ekstraksi Tanaman Obat}

Serbuk tanaman obat pegagan (Centella asiatica) dan majapahit (Cresintia cujete) ditimbang 100 gram dan dimaserasi dengan $400 \mathrm{ml}$ etanol absolut selama 24 jam dengan pengadukan. Setelah perlakuan maserasi selama 24 jam larutan disaring dengan menggunakan vakum dan kertas saring untuk memisahkan ampas dan filtratnya, filtrat kemudian dievaporasi dengan rotary evaporator vakum untuk menguapkan pelarutnya, sehingga diperoleh ekstrak kental dari tanaman obat dan kemudian dikeringkan agar diperoleh ekstrak kering. Hasil ekstrak kering kemudian dibuat variasi komposisi konsentrasi pegagan (Centella asiatica):majapahit (Cresintia cujete) sebesar 75\%, 50\% dan 25\%.

\section{Uji Kualitatif Total Fenol dalam Sampel}

Penentuan fenol total seperti yang dilakukan Ahda, (2014) dengan menggunakan metode folin Ciocalteu. Sebanyak 100,0 mg ekstrak etanol kulit 
pegagan (Centella asiatica) dan majapahit (Cresintia cujete) dilarutkan sampai volume 25,0 ml kemudian diambil $0,3 \mathrm{~mL}$ ditambahkan 1,5 $\mathrm{mL}$ reagen fenol yaitu folin Ciocalteu (1:10) diaduk sampai homogen. Setelah 5 menit, ditambahkan $1,2 \mathrm{~mL}$ sodium karbonat 7,5 \% dan diamkan selama 60 menit. Kemudian diamati warna yang terbentuk secara kolorimetri.

\section{Penentuan Aktifitas Penangkapan}

\section{Radikal Bebas DPPH}

Penentuan aktivitas antioksidan dilakukan dengan cara $3 \mathrm{~mL}$ larutan DPPH dengan konsentrasi $1 \mathrm{mM}$ dalam etanol ditambah dengan $1 \mathrm{~mL}$ ekstrak larutan sampel. Konsentrasi larutan sampel yang dibuat adalah 10, 50, 100, 150, $200 \mathrm{ug} / \mathrm{mL}$. Campuran didiamkan selama 30 menit. Larutan ini kemudian diukur absorbansinya pada panjang gelombang $515 \mathrm{~nm}$.

\section{Pembahasan}

Karakterisasi gugus fungsi ekstrak etanol Pegagan dan Cresintia cujete

Senyawa aktif dalam ekstrak etanol pegagan (Centella asiatica) dan majapahit (Cresintia cujete) dikarakterisasi dengan spektroskopi infrared (IR). Hal ini bertujuan untuk melihat gugus fungsional senyawa aktif yang ada dalam ekstraks tersebut (Gambar 1).
Gambar 1. Menunjukkan bahwa vibrasi gugus fungsional senyawa aktif yang terdapat pada ekstrak etanol pegagan (Centella asiatica) dan majapahit (Cresintia cujete) memiliki vibrasi pada bilangan daerah sekitar 3300-3500 $\mathrm{cm}^{-1}$ yang merupakan jenis vibrasi berasal dari gugus hidroksil (-OH). Hasil spectrum juga menunjukkan adanya jenis vibrasi $\mathrm{C}-\mathrm{H}$ alkana pada bilangan gelombang 2800-3000 $\mathrm{cm}^{-1}$, metil pada daerah $1425 \mathrm{~cm}^{-1}$, metilen pada daerah $1350 \mathrm{~cm}^{-1}$ dan jenis vibrasi $\mathrm{C}-\mathrm{H}$ alkena aromatis muncul pada bilangan gelombang pada daerah $1500 \mathrm{~cm}^{-1}$ dan 1630 $\mathrm{cm}^{-1}$.

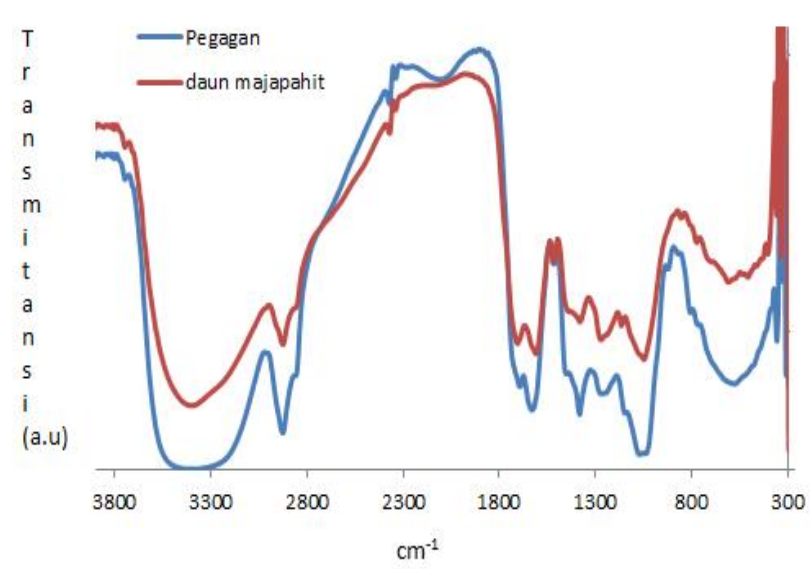

Gambar 1. Hasil Karakterisasi Spektra FTIR Ekstraks pegagan (Centella asiatica) dan majapahit (Cresintia cujete)

\section{Uji Kualitatif Fenol Total}

Ekstrak pegagan (Centella asiatica) dan majapahit (Cresintia cujete) dilakukan uji kualitatif dengan pereaksi folin ciocelteau untuk mendeteksi senyawa aktif fenol total 
dalam ekstrak tersebut. Proses uji kualitatif fenol total dalam ekstraks pegagan (Centella asiatica) dan majapahit (Cresintia cujete) menggunakan pereaksi Folin Ciocelteau 10\%. Hasil menunjukkan adanya perubahan warna menjadi biru (Gambar 2). Warna biru yang terbentuk karena karena adanya proses reaksi oksidasi reduksi. Senyawa yang mengandung gugus fenolik akan mengalami oksidasi sedangkan Folin Ciocalteu akan mengalami reduksi. Proses oksidasi reduksi ini yang mendasar penetapan kadar total fenol dalam ekstrak etanol pegagan (Centella asiatica) dan majapahit (Cresintia cujete). Pereaksi folin ciocalteau akan mengalami proses reduksi dari fosfomolibdattungsten menjadi heteropolimolibdenum biru dengan terbentuknya warna biru (Walker, 2002). Hal ini sesuai seperti yang dilaporkan oleh sugiat, dkk, (2010), yang melakukan penetuan kadar total fenol pada dedak dengan pereaksi Folin Ciocalteu.

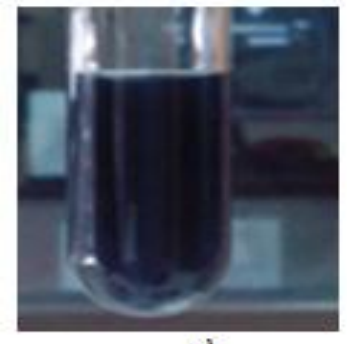

a)

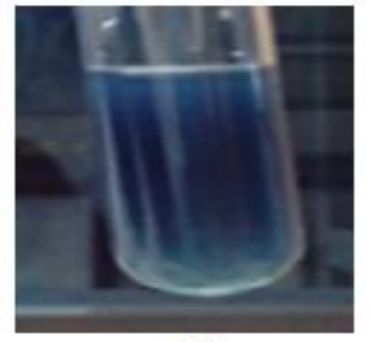

b)
Gambar 2. Hasil Reaksi Fenol Total dengan Pereaksi Folin Ciocelteau ; a) Ekstrak Etanol majapahit (Cresintia cujete), b) Ekstrak Etanol Pegagan (Centella asiatica)
Gambar 2. Menunjukkan adanya perbedaan hasil uji kualitatif pada ekstraks etanol pegagan (Centella asiatica) dan majapahit (Cresintia cujete). Ekstrak majapahit (Cresintia cujete) menghasilkan warna yang lebih biru dibandingkan ekstraks pegagan (Centella asiatica) setelah direaksikan dengan Folin Ciocalteu. Menurut Maurya dan Singh (2010) bahwa reagen Folin Ciocalteu sensitif pada reduksi oleh senyawa seperti polifenol menyebabkan terbentuknya senyawa biru. Hasil de Oliveira dkk., (2012) menyebutkan bahwa reagen Folin Ciocalteu dapat digunakan untuk mendapatkan estimasi kasar jumlah total fenol yang ada dalam ekstrak walaupun tidak spesifik hanya polifenol saja akan tetapi subtrat lainnya yang dapat dioksidasi oleh reagen Folin Ciocalteu.

\section{Uji Aktivitas Penghambatan DPPH}

Proses optimasi komposisi ekstrak pegagan dan Cresintia cujete pada penelitian ini dilakukan dengan melihat komposisi yang memiliki aktifitas penangkapan terhadap radikal bebas DPPH yang paling baik. Nilai yang menunjukkan aktifitas penangkapan radikal bebas DPPH disimbulkan dengan Inhibition Concentration fifty $\left(\mathrm{IC}_{50}\right)$. Menurut Yung-chi dan Prusoff (1973) menyatakan bahwa IC $_{50}$ merupakan nilai yang menyatakan 
konsentrasi inhibitor yang dibutuhkan untuk menghasilkan 50 per penghambatan persen dari reaksi enzimatik pada konsentrasi substrat tertentu. Oleh karena itu, aktifitas penangkapan radikal bebas DPPH yang terbaik adalah komposisi ekstraks yang menghasilkan nilai $\mathrm{IC}_{50}$ terkecil. Hal ini menandakan bahwa dengan konsentrasi rendah memiliki kemampuan menghambat $50 \%$ radikal bebas DPPH.

Hasil optimasi komposisi ekstraks daun pegagan (Centella asiatica) dan majapahit (Cresintia cujete) menunjukkan bahwa komposisi ekstraks etanol 30\% pegagan (Centella asiatica) dan 70\% majapahit (Cresintia cujete) menghasilkan slope paling besar dengan nilai sebesar dibandingkan hasil yang diperoleh dari komposisi ekstrak lainnya (Gambar 3).

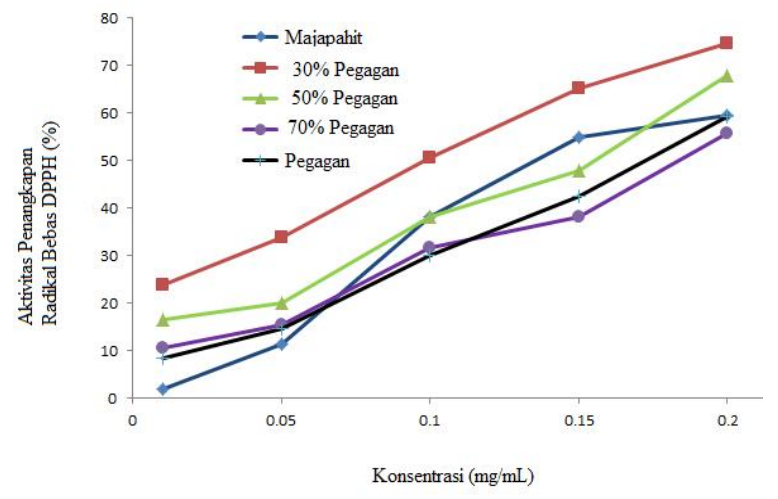

Gambar 3. Hubungan Antara Konsentrasi Ekstrak Etanol Pegagan (Centella asiatica) dan Majapahit (Cresintia cujete)

Gambar 3 menunjukkan bahwa komposisi ekstrak etanol pegagan (Centella asiatica):majapahit $($ Cresintia cujete $)=$ 30:70 memiliki hubungan dengan persamaan garis $y=277,64 x+21,32$. Persamaan garis ini digunakan untuk menentukan nilai $\mathrm{IC}_{50}$. Berdasarkan persamaan garis tersebut, slope yang dihasilkan oleh komposisi ekstrak daun pegagan (Centella asiatica) dan majapahit $($ Cresintia $\quad$ cujete $)=\quad 30: 70 \quad$ terbesar dibandingkan komposisi lainnya. Menurut Marxen, dkk., (2007) menyatakan bahwa slope yang dihasilkan dapat digunakan untuk mengukur kemampuan antioksidan. Hal ini menyebabkan komposisi ekstraks etanol pegagan (Centella asiatica) dan majapahit $($ Cresintia cujete $)=30: 70$ memiliki $\mathrm{IC}_{50}$ yang paling kecil (Gambar 4).

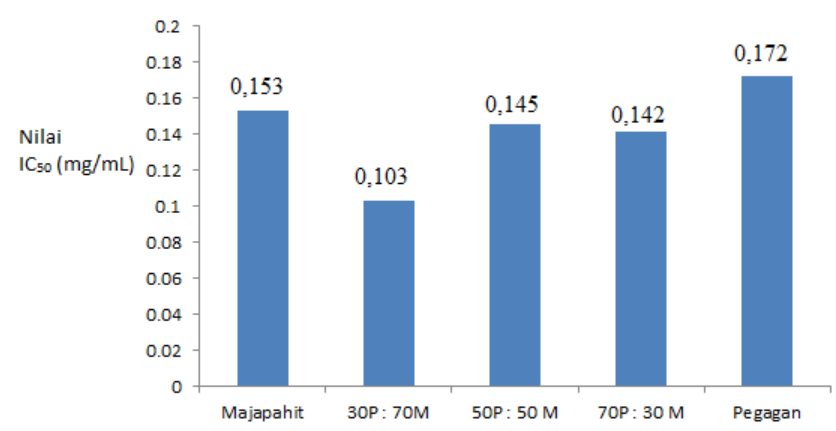

Gambar 4. Nilai $\mathrm{IC}_{50}$ pada Penangkapan Radikal Bebas DPPH (M: Majapahit (Cresintia cujete) dan P: Pegagan)

Gambar 4. Menunjukkan hasil $\mathrm{IC}_{50}$ berbagai komposisi ekstrak etanol pegagan (Centella asiatica) dan majapahit (Cresintia cujete). Komposisi ekstrak etanol pegagan (Centella asiatica) dan majapahit (Cresintia 
cujete $)=30: 70$ memiliki $\mathrm{IC}_{50}$ sebesar 0,103 $\mathrm{mg} / \mathrm{mL}$. Nilai tersebut mengindikasikan bahwa dengan konsentrasi ekstrak sebesar $0,103 \mathrm{mg} / \mathrm{mL}$ mampu menghambat 50\% DPPH. Hasil ini juga menunjukkan bahwa komposisi ekstrak daun pegagan (Centella asiatica) dan majapahit (Cresintia cujete) $=$ 30:70 memililiki $\mathrm{IC}_{50}$ terkecil dan disimpulkan bahwa komposisi ekstrak pegagan (Centella asiatica) dan majapahit $($ Cresintia cujete $)=30: 70$ pegagan memiliki aktivitas terbaik sebagai sumber antioksidan alami.

\section{Kesimpulan}

Hasil penelitian menunjukkan bahwa baik ekstrak etanol pegagan (Centella asiatica) dan majapahit (Cresintia cujete) memiliki kandungan total fenol yang ditunjukkan dengan adanya kemampuan mereduksi reagen Folin Ciocalteu menjadi berwarna biru. Hasil optimasi komposisi ekstrak etanol pegagan (Centella asiatica): majapahit $($ Cresintia cujete $)=30: 70$ memiliki aktifitas penangkapan radikal bebas terhadap DPPH yang paling baik dibandingkan ekstraks etanol pegagan (Centella asiatica) dan majapahit (Cresintia cujete). Nilai $\mathrm{IC}_{50}$ untuk komposisi ekstrak etanol pegagan (Centella asiatica) dan majapahit $($ Cresintia cujete $)=30: 70$ sebesar $0,103 \mathrm{mg} / \mathrm{mL}$.

\section{Pustaka}

Agarwal, M., and Chauhan, S., 2015, AntiMycobaterial Potential of Crescentia cujete (Bignoniaceae), International Journal of Advanced Research in Botany (IJARB), 1 (1), 1-9

Ahda, M., 2014., Pengaruh Variasi Konsentrasi Etanol sebagai Pengekstrak Kulit Manggis terhadap Kandungan Fenol Total, Eksakta, 14, (2), 61-70

Das, N., Islam, M.E., Jahan, N., Islam, M.S., Khan, A., Islam, M.R., and Parvin, M.S., 2014, Antioxidant activities of ethanol extracts and fractions of Crescentia cujete leaves and stem bark and the involvement of phenolic compounds, BMC Complementary and Alternative Medicine, 14 (45), 19

de Oliveira, A.M.F., Pinheiro, L.S., Pereira, C.K.S., Matias, W.N., Gomes, R.A., Chaves, O.S., de Souza, M.F.V., de Almeida, R.N., and de Assis, T.S., 2012, Total Phenolic Content and Antioxidant Activity of Some Malvaceae Family Species, Antioxidants, 1, 33-43

Ejelonu BC., Lasisi AA., Olaremu AG,. and Ejelonu OC., 2011, The chemical constituents of calabash (Crescentia cujete), African Journal of Biotechnology, 10 (84), 19631-19636

Herlina, 2010, Pengaruh Triterpen Total Pegagan (Centella asiatica(L)Urban) Terhadap Fungsi Kognitif Belajar dan Mengingat pada Mencit Jantan Albino(Mus musculus), Jurnal Penelitian Sains, 1006 (06), 20-24

Kim, W-J., Kim, J., Veriansyah, B., Kim, JD., Lee, Y-W., Oh, S-G., dan Tjandrawinata, R., 2009. Extraction of bioactive component from Centella asiatica using subcritical water. The Journal of Supercritical Fluids, 48:211-216. 
Mahbub, K.R., Hoq, M.M., Ahmed, M.M.,Sarker, A., 20011, In Vitro Antibacterial Activity of Crescentia Cujete and Moringa Oleifera, Bangladesh Research Publication Journal, 5 (4), 337-343

Marxen, K., Vanselow , K.H., Lippemeier, S., Hintze, R., Ruser, A., and Hansen, U.P., 2007, Determination of DPPH Radical Oxidation Caused by Methanolic Extracts of Some Microalgal Species by Linear Regression Analysis of Spectrophotometric Measurements, Sensors, 7, 2080-2095

Maurya, S., and Singh, D., 2010, Quantitative Analysis of Total Phenolic Content in Adhatoda vasica Nees Extracts, IJPRIF, 2, (4), 24032406

Pietta P.G., 1999. Flavonoids antioxidants, Review, J. Nat. Prod., 63, 1035

Sugiat, D., Hanani, E., Mun'im, A., 2010, Aktifitas Antioksidan dan Penetapan Kadar Fenol Total Ekstrak Metanol Dedak Beberapa Varietas Padi (Oryza Sativa L.), Majalah Ilmu Kefarmasian, VII (1), 24-33

Sutrisno, E., Adnyana, I.K., Sukandar, E.Y., Fidrianny, I. dan Lestari, T., 2014, Kajian Aktivitas Penyembuhan Luka dan Antibakteri Binahong (Anredera cordifolia (Ten.) Steenis, Pegagan (Centella asiatica (L.) Urban) Serta Kombinasinya terhadap Bakteri Staphylococcus aureus dan Pseudomonas aeruginosa dari pasien Luka Kaki Diabetes, BionaturaJurnal Ilmu-ilmu Hayati dan Fisik, $16,(2), 78-82$

Walker, J.M., 2002, The Protein Protocols Handbook, $2^{\text {nd }}$ Edition, Humana Press Inc., Totowa, New Jersey

Yung-chi, C., and Prusoff, W.H., 1973, Relationship between the inhibition constant $\left(K_{I}\right)$ and the concentration of inhibitor which causes 50 per cent inhibition $\left(I_{50}\right)$ of an enzymatic reaction, Biochemical Pharmacology, 22, (23), 3099-3108 